\title{
Effectiveness of Psychological and Educational Interventions to Prevent Depression in Primary Care: A Systematic Review and Meta-Analysis
}

\author{
Sonia Conejo-Cerón, PbD \\ Patricia Moreno-Peral, PbD \\ Alberto Rodríguez-Morejón, $\mathrm{PbD}$ \\ Emma Motrico, PbD \\ Desirée Navas-Campaña, PbD \\ Alina Rigabert, MSc \\ Carlos Martín-Pérez, MD, PbD \\ Antonina Rodríguez-Bayón, MD, \\ $\mathrm{PbD}$ \\ María Isabel Ballesta-Rodríguez, \\ $M D, P b D$ \\ Juan de Dios Luna, PbD \\ Javier García-Campayo, MD, PbD \\ Miquel Roca, MD, PbD \\ Juan Ángel Bellón, MD, PbD
}

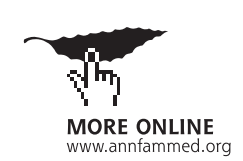

Conflicts of interest: authors report none.

\section{CORRESPONDING AUTHOR}

Sonia Conejo-Cerón

Unidad de Investigación

Distrito de Atención Primaria

Málaga-Guadalhorce

C/ Sevilla 23, $3^{\text {a }}$ planta

29009 Málaga, Spain

soniafundacionimabis@hotmail.com

\begin{abstract}
PURPOSE Although evidence exists for the efficacy of psychosocial interventions to prevent the onset of depression, little is known about its prevention in primary care. We aimed to evaluate the effectiveness of psychological and educational interventions to prevent depression in primary care.

METHODS We conducted a systematic review and meta-analysis of relevant randomized controlled trials (RCTs) examining the effect of psychological and educational interventions to prevent depression in nondepressed primary care attendees. We searched MEDLINE, PsycINFO, Web of Science, OpenGrey Repository, Cochrane Central Register of Controlled Trials, and other sources up to May 2016. At least 2 reviewers independently evaluated the eligibility criteria, extracted data, and assessed the risk of bias. We calculated standardized mean differences (SMD) using random-effects models.

RESULTS We selected 14 studies (7,365 patients) that met the inclusion criteria, 13 of which were valid to perform a meta-analysis. Most of the interventions had a cognitive-behavioral orientation, and in only 4 RCTs were the intervention clinicians primary care staff. The pooled SMD was $-0.163(95 \% \mathrm{Cl},-0.256$ to $-0.070 ; P=.001)$. The risk of bias and the heterogeneity $\left(1^{2}=20.6 \%\right)$ were low, and there was no evidence of publication bias. Meta-regression detected no association between SMD and follow-up times or SMD and risk of bias. Subgroup analysis suggested greater effectiveness when the RCTs used care as usual as the comparator compared with those using placebo.
\end{abstract}

CONCLUSIONS Psychological and educational interventions to prevent depression had a modest though statistically significant preventive effect in primary care. Further RCTs using placebo or active comparators are needed.

Ann Fam Med 2017;15:262-271. https://doi.org/10.1370/afm.2031.

\section{INTRODUCTION}

ccording to the World Health Organization, major depressive dis-
order affects about 350 million people worldwide. ${ }^{1}$ An international
study found the average 12 -month prevalence of major depression to be $5 \% .{ }^{2}$ In primary care, though, this figure is higher $(11 \%) .{ }^{3}$ About $60 \%$ to $70 \%$ of patients with acute depression experience suicidal ideas, with the actual incidence of suicide in depressive patients being $10 \%$ to $15 \% .{ }^{4}$ Patients with a specific physical illness who develop depression have an excess mortality of $52 \% .{ }^{5}$ In terms of global disease burden measured in disability-adjusted life years, major depressive disorder increased by $37 \%$ between 1990 and $2010^{6}$ and is projected to become the single leading cause of disease burden by 2030 in high-income countries. ${ }^{7}$

Two ways exist to reduce the disease burden of depression: treatment and prevention of new cases. Despite effective treatments for depression, the disease burden of depression can be reduced by only $20 \%$; not all cases are recognized, and when recognized, not all patients receive appropriate therapy or adhere to treatment. ${ }^{8}$ 
In recent decades interest in prevention has grown, ${ }^{9}$ and it is now a key objective in the strategic plan of the National Institute of Mental Health (NIMH) ${ }^{10}$ Hundreds of randomized controlled trials (RCTs) designed to prevent depression, as well as dozens of systematic reviews, have been undertaken on this topic. ${ }^{11-22}$ Most RCTs to prevent depression examined interventions with a cognitive-behavioral orientation. Additionally, more than $70 \%$ of RCTs to prevent depression have been conducted in children and adolescents, and only $24 \%$ of RCTs to prevent depression lasted longer than 12 months of follow-up. ${ }^{23}$ Although interventions to prevent depression are beneficial, their effect sizes are small, ${ }^{23,24}$ and no conclusive data exist on the superiority of any particular intervention. ${ }^{24}$

Primary health care services are the ideal setting in which to undertake disease prevention strategies for many illnesses, including depression. ${ }^{25}$ At the patient level, many people at risk of depression are seen in general practice. At the population level, primary care serves defined communities, so that prevention can be population based. Although some trials for primary prevention of depression in primary care have been undertaken, no systematic review or meta-analysis of these trials has yet been conducted.

Our objective was to evaluate the effectiveness of psychological and educational interventions to prevent depression in primary care.

\section{METHODS}

We followed the Preferred Reporting Items for Systematic Reviews and Meta-Analyses (PRISMA) guidelines. ${ }^{26}$ The protocol was registered in the International Prospective Register of Systematic Reviews (PROSPERO, registration number: CRD42014006067).

\section{Search Strategies and Screening Procedures}

We searched MEDLINE (via PubMed), PsycINFO, Embase, Web of Science (WOS), OpenGrey Repository (System for Information on Grey Literature in Europe), and Cochrane Central Register of Controlled Trials (CENTRAL) from inception to May 2016 without restrictions. The last search was on May 27, 2016. We reviewed the reference lists of relevant meta-analyses and reviews, ${ }^{11-24}$ as well as retrieved articles, to find additional publica- tions. We also contacted experts in the field to identify other pertinent articles.

The search strategy included the following terms: "randomized controlled trial," "depressive disorder," "prevention," "primary health care," and "intervention." Search results were restricted by the term "randomized controlled trial." The search strategy was developed first in MEDLINE (via PubMed) and later adapted to all databases (Supplemental Appendix, available at http:// www.annfammed.org/content/15/3/262/suppl/DC1).

\section{Selection Criteria}

Studies had to meet specific inclusion and exclusion criteria (Table 1).

We selected RCTs because they provide more evidence on causality and are considered a reference standard for clinical trials. ${ }^{27}$ We included all primary care patients, excluding those with depression at baseline, which allowed us to separate the effectiveness of prevention from that of treatment. We focused on psychological and educational interventions because they share the same mechanism of action, facilitating changes in attitudes and behavior, and because most interventions to prevent depression are of this type. ${ }^{28}$ All languages were considered.

\section{Study Selection}

The entire selection process was reviewed independently by the first 2 authors (S.C.C. and P.M.P.). In the event of disagreement, a third author (J.A.B.) was consulted. The degree of agreement between the first 2 authors was excellent $(\kappa=0.78 ; 95 \% \mathrm{CI}$, $0.59-0.98){ }^{29,30}$

\begin{tabular}{|c|c|c|}
\hline Aspect Considered & Inclusion Criteria & Exclusion Criteria \\
\hline Setting & Primary health care ${ }^{\mathrm{a}}$ & Other settings \\
\hline Population & $\begin{array}{l}\text { Primary care population not } \\
\text { depressed at baseline }{ }^{b}\end{array}$ & $\begin{array}{l}\text { Primary care population } \\
\text { depressed at baseline }\end{array}$ \\
\hline Type of intervention & $\begin{array}{l}\text { Psychological or educational } \\
\text { interventionc }\end{array}$ & $\begin{array}{l}\text { Pharmacological and physi- } \\
\text { cal interventions }\end{array}$ \\
\hline Comparator & $\begin{array}{l}\text { Care as usual, no intervention, } \\
\text { waiting list, attention control, } \\
\text { or placebo }\end{array}$ & Other controls \\
\hline Design & $\mathrm{RCT}$ & Other designs \\
\hline Outcome & $\begin{array}{l}\text { Prevention of depression (inci- } \\
\text { dence of depression or reduc- } \\
\text { tion of depressive symptoms) }\end{array}$ & Other outcomes \\
\hline Language & All languages & No restrictions \\
\hline \multicolumn{3}{|c|}{$\mathrm{RCT}=$ randomized controlled trial. } \\
\hline \multicolumn{3}{|c|}{$\begin{array}{l}\text { a All patients included in the RCTs must be recruited in primary care, health centers, or general practices } \\
\text { b The entire spectrum of nondepressed patients included ranges from nondepressive symptoms ( } 0 \text { symp- } \\
\text { toms) to subthreshold forms of depression (eg, minor depression or subsyndromal depression). } \\
\text { ' Educational interventions provide information about depression through lectures or fact sheets, } \\
\text { whereas psychological interventions attempt to change how people think using a variety of different } \\
\text { strategies (eg, cognitive behavioral or interpersonal therapy). }\end{array}$} \\
\hline
\end{tabular}




\section{Data Extraction}

Data were independently extracted by the 3 reviewing authors using a purposefully designed data extraction form. Discrepancies between the reviewers were reconciled by consensus. Wherever necessary, the reviewers contacted the authors of published articles to obtain missing data.

\section{Risk of Bias}

We assessed methodological quality using the Cochrane Collaboration risk of bias tool. ${ }^{31}$ This tool measures the quality of RCTs through 6 criteria: random sequence generation, allocation concealment, blinding of participants and clinicians, blinding of outcome assessment, incomplete outcome data, and selective reporting. All assessments of risk of bias were performed independently by 2 authors (S.C.C. and P.M.P.) and discrepancies were resolved by consensus between them. There was excellent inter-researcher agreement (intraclass correlation coefficient $=0.85$; $95 \% \mathrm{CI}, 0.74-0.92){ }^{32}$

\section{Statistical Analysis}

We used Comprehensive Meta-Analysis Software, version 3.0 (Biostat, Inc) for all analyses.

We used standardized mean difference (SMD) as effect size because most RCTs included in our metaanalysis assessed differences in depressive symptoms. For each study, we first calculated the SMD by combining the SMD at different follow-up times into a single estimate as average. We then calculated the pooled SMD of all RCTs, as well as its 95\% CI. Cohen proposed the following interpretation for this effect size: 0.2 smalli 0.5 medium, and 0.8 large. ${ }^{33}$ Negative SMDs indicated a better outcome (reduction of depressive symptoms) in the intervention group. The random-effects model assumes that the included studies are drawn from populations that may differ and we believed this model was more appropriate to our study. ${ }^{31}$ We conducted all analyses using both fixedand random-effects models.

As a test of heterogeneity of effect sizes, we estimated the $\mathrm{I}^{2}$ statistic, which can be expressed as a percentage, where a value of $0 \%$ indicates no heterogeneity, and $25 \%, 50 \%$, and $75 \%$ can be interpreted as low, moderate, and high levels of heterogeneity, respectively. ${ }^{34}$ We also calculated the $\mathrm{Q}$ statistic and its $P$ value.

Publication bias was evaluated by inspecting the funnel plot on the primary outcome measure and by Duval and Tweedie's trim-and-fill procedure, ${ }^{35}$ which yields an estimate of the effect size after adjusting for publication bias. We also performed Begg and Mazumdar rank correlation and Egger's test, which quantify the bias captured by the funnel plot. We calculated the Rosenthal's fail-safe $\mathrm{N}$ test, which computes the number of missing studies (with SMD of 0 ) that would need to be added to the analysis to yield a statistically insignificant overall effect.

Because the SMD could differ at varying follow-up periods, we conducted sensitivity analyses at the first and last follow-up. We also conducted subgroup analyses according to type of prevention, country, age, comparator, clinician, intervention format, number of sessions, and sample size. Meta-regression analyses were conducted to see whether differences existed in effect sizes with time or depending on their risk of bias.

\section{RESULTS}

\section{Search Results}

A total of 35 articles were retrieved for further fulltext evaluation of the inclusion criteria. Of these 35 articles, 19 were excluded (Table S1, Supplemental Appendix, available at http://www.annfammed.org/ content/15/3/262/suppl/DC1), leaving a total of 14 $\mathrm{RCTs}^{36-50}$ (reported in 16 publications) that met all the inclusion criteria and that were selected. Figure 1 displays the flowchart describing the inclusion process.

\section{Characteristics of Included Studies}

The $14 \mathrm{RCTs}^{36-50}$ were published between 1993 and 2016. Six RCTs were conducted in the United States, 3 in Spain, 2 in the Netherlands, 2 in the United Kingdom and 1 in China; 9 were aimed at adults and 5 at specific populations. Concerning type of prevention, 9 evaluated the indicated prevention, 4 evaluated selective prevention, and 1 evaluated universal prevention. Overall, the RCTs evaluated a total of 7,365 participants: 4,018 in the intervention group and 3,287 in the control group; 1 RCT did not report information about the intervention and control sample size separately. ${ }^{50}$ The population size of the RCTs ranged from 29 to 3,326 (median =169). We excluded the antidepressant arm from 3 RCTs. ${ }^{38,48,49}$

The intervention orientation was based on the principle of cognitive behavioral therapy (CBT) in 12 RCTs. The comparators in 11 RCTs were care as usual, no intervention, or waiting list.

The intervention format was delivered as individual sessions in 10 RCTs and in 4 as group sessions. The number of sessions ranged from 3 to 12 (median $=6$ ). The interventions were delivered by primary care staff in only 4 RCTs.

Concerning outcome, 9 RCTs measured depressive symptoms, 2 measured incidence of depression, and 3 measured symptoms and incidence. 
The follow-up periods varied between 7 weeks and 60 months (median $=12$ months). Six RCTs reported a follow-up of greater than 12 months and 5 had a follow-up of less than 6 months. More details about the 14 RCTs included are displayed in Table 2.

\section{Risk of Bias in Included Studies}

Ten RCTs had a low ( 4 or fewer points), 1 had a moderate (5 to 6 points), and 3 had a high ( 7 or more points) risk of bias. Table 2 shows details about the risk of bias for each study.

\section{Figure 1. Flowchart of the studies reviewed.}

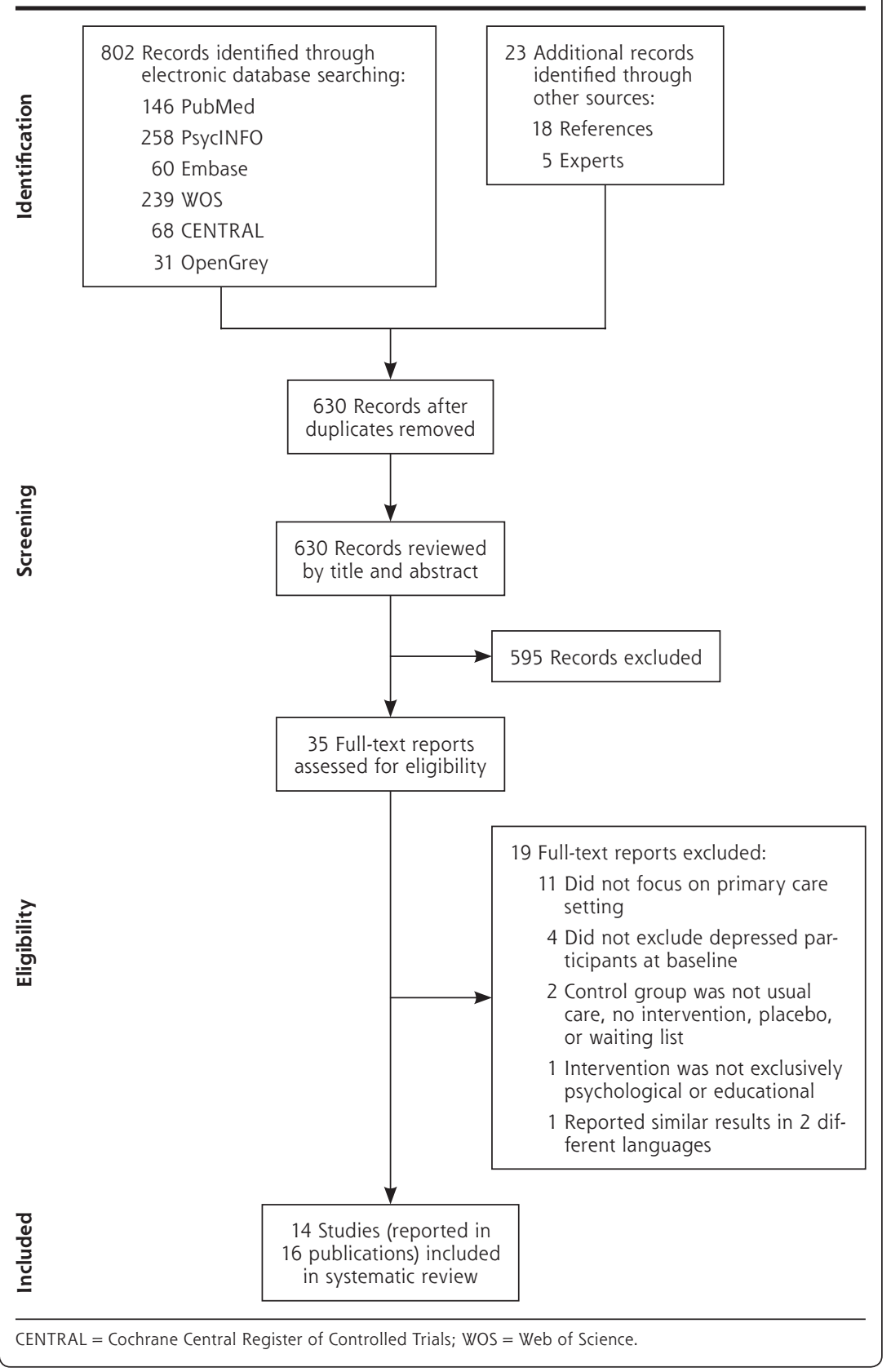

\section{Effectiveness of the Interventions to Prevent Depression}

For meta-analysis calculations we used 13 RCTs

because $1 \mathrm{RTC}^{50}$ of the 14 included in the systematic review did not report the necessary data. The pooled SMD was -0.158 (95\% CI, -0.234 to $-0.082 ; P=.000)$ for the fixed-effects model and $-0.163(95 \% \mathrm{CI},-0.256$ to $\left.-0.070_{i} P=.001\right)$ for the random-effects model $_{i}$ the odds ratio (OR) of this latter effect size, transformed by the Comprehensive Meta-Analysis Software, was $0.744(95 \% \mathrm{CI}, 0.629$ to $0.881 ; P=.001)$, which means that psychological and educational interventions in primary care had a small, although statistically significant, effect to prevent depression. Heterogeneity was low $\left(I^{2}=20.6 \%\right)$ and statistically nonsignificant $(\mathrm{Q}=15.12 ; 12$ $\left.d f_{i} P=0.235\right)$. Figure 2 is a forest plot for the overall and individual effect sizes.

\section{Sensitivity Analyses}

Because the effect sizes for the fixed-and the random-effects models were very similar, we report the results for only the random-effects model. The pooled SMD using the first evaluation over time (posttreatment) of each RCT was similar to the last evaluation (Table 3). When we excluded from the analysis the only RCT that used the reduction of depressive symptoms as a secondary outcome ${ }^{43}$ the pilot study of Brugha, ${ }^{45}$ or both studies ${ }_{1}^{43,45}$ the pooled SMDs were then similar (Table 3).

\section{Meta-Regression}

The effect sizes increased with time $(\beta=-0.0094 ; 95 \% \mathrm{CI}$, -0.0170 to $-0.0018 ; P=.015$ ). When the variable type of comparator was included in the equation, however, this effect was not statistically significant ( $\beta=-0.0076 ; 95 \% \mathrm{CI},-0.017$ to $.001 ; P=.095)$. There was no statistically significant association between effect size and risk of bias $(\beta=-0.024 ; 95 \% \mathrm{CI},-0.083$ 
Table 2. Randomized Clinical Trials to Prevent Depression in Primary Care

\begin{tabular}{|c|c|c|c|c|}
\hline $\begin{array}{l}\text { Author, Year } \\
\text { Country }\end{array}$ & $\begin{array}{l}\text { Target Population, } \\
\text { Type of Prevention }\end{array}$ & Inclusion Criteria & $\begin{array}{l}\text { Sample (Control/ } \\
\text { Intervention) } \\
\text { No. }\end{array}$ & Care Management \\
\hline $\begin{array}{l}\text { Barrett et al, }{ }^{49} 2001^{\mathrm{b}} \\
\quad \text { (United States) }\end{array}$ & $\begin{array}{l}\text { Adults (18-59 y) } \\
\text { Indicated }^{c}\end{array}$ & $\begin{array}{c}\text { Minor depression } \\
\text { (HRSD } \geq 10 ; \text { PRIME-MD) }\end{array}$ & $74(38 / 36)$ & $\begin{array}{l}\text { 1. PST-PC } \\
\text { 2. Placebo plus clinical management }\end{array}$ \\
\hline $\begin{array}{l}\text { Bellón et al, }{ }^{47} 2016 \\
\text { (Spain) }\end{array}$ & $\begin{array}{c}\text { Adults (18-75 y) } \\
\text { Universald }^{\mathrm{d}}\end{array}$ & No MD in past 6 mo (CIDI) & $3,326(1,663 / 1,663)$ & $\begin{array}{l}\text { 1. Biopsychosocial intervention } \\
\text { 2. CAU }\end{array}$ \\
\hline $\begin{array}{l}\text { Brugha et al, }{ }^{44} 2011 \\
\text { (United Kingdom) }\end{array}$ & $\begin{array}{l}\text { Women postnatally } \\
\text { Selective }\end{array}$ & No depression (EPDS <12) & $2,241(767 / 1,474)$ & $\begin{array}{l}\text { 1. } C B A / P C A \\
\text { 2. CAU }\end{array}$ \\
\hline $\begin{array}{l}\text { Brugha et al, }{ }^{45} 2016 \\
\text { (United Kingdom) }\end{array}$ & $\begin{array}{l}\text { Pregnant women } \\
\text { Selective }\end{array}$ & No depression (EPDS <12) & $186(83 / 103)$ & $\begin{array}{l}\text { 1. } \mathrm{CBA} \\
\text { 2. } \mathrm{CAU}\end{array}$ \\
\hline $\begin{array}{l}\text { Frank et al, }{ }^{38} 2002^{b} \\
\quad \text { (United States) }\end{array}$ & $\begin{array}{l}\text { Adults }(\geq 18 \text { y) } \\
\text { Indicated }\end{array}$ & $\begin{array}{c}\text { Minor depression } \\
\text { (HRSD } \geq 10 ; \text { PRIME-MD) }\end{array}$ & $168(89 / 79)$ & $\begin{array}{l}\text { 1. PST-PC } \\
\text { 2. Placebo plus clinical management }\end{array}$ \\
\hline $\begin{array}{l}\text { García-Campayo et al, }{ }^{43} \\
2010 \text { (Spain) }\end{array}$ & $\begin{array}{l}\text { Adults }(18-65 \text { y) } \\
\text { Selective }\end{array}$ & $\begin{array}{l}\text { No DSM-IV Axis I psychiat- } \\
\text { ric disorders (SPPI) }\end{array}$ & $104(52 / 52)$ & $\begin{array}{l}\text { 1. Psychoeducational } \\
\text { 2. No intervention }\end{array}$ \\
\hline $\begin{array}{l}\text { Gillham et al, }{ }^{40} 2006 \\
\text { (United States) }\end{array}$ & $\begin{array}{l}\text { Early adolescents (11-12 y) } \\
\text { Indicated }\end{array}$ & No MD (CDI $\geq 7 / 9$; DICA-R) & $271(124 / 147)$ & $\begin{array}{l}\text { 1. } C B T(P R P) \\
\text { 2. } C A U\end{array}$ \\
\hline $\begin{array}{l}\text { González et al, }{ }^{50} 2006 \\
\text { (Spain) }\end{array}$ & $\begin{array}{l}\text { Adults }(25-55 \text { y) } \\
\text { Indicated }\end{array}$ & $\begin{array}{l}\text { No depressive disorder } \\
\text { (DSM-IV) }\end{array}$ & 60 (NR/NR) & $\begin{array}{l}\text { 1. CBT } \\
\text { 2. Encouraging personal resources } \\
\text { 3. Social support } \\
\text { 4. Waiting list }\end{array}$ \\
\hline $\begin{array}{l}\text { Lynch et al, }{ }^{37} 1997 \\
\text { (United States) }\end{array}$ & $\begin{array}{l}\text { Adults ( } \geq 18 \text { y) } \\
\text { Indicated }\end{array}$ & $\begin{array}{l}\text { Minor depression (MOS } \\
\text { Depression Screening Inven- } \\
\text { tory >cutoff; DIS) }\end{array}$ & $29(14 / 15)$ & $\begin{array}{l}\text { 1. PST } \\
\text { 2. CAU }\end{array}$ \\
\hline $\begin{array}{l}\text { Muñoz et al, }{ }^{36} \\
\text { 1993-1995 (United } \\
\text { States) }\end{array}$ & $\begin{array}{l}\text { Adults }(\geq 18 \text { y) } \\
\text { Selective }^{e}\end{array}$ & $\begin{array}{c}\text { No MD in past } 6 \text { months } \\
\text { (DIS) }\end{array}$ & $150(78 / 72)$ & $\begin{array}{l}\text { 1. CBT } \\
\text { 2. No intervention or information } \\
\text { by videotape }\end{array}$ \\
\hline $\begin{array}{l}\text { van't Veer-Tazelaar } \\
\text { et al, }{ }^{41,42} \text { 2009-2011 } \\
\text { (the Netherlands) }\end{array}$ & $\begin{array}{l}\text { Elderly ( } \geq 75 \text { y) } \\
\text { Indicated }^{c}\end{array}$ & $\begin{array}{c}\text { Subthreshold depressive } \\
\text { symptoms, no MDE (CES-D } \\
\geq 16 ; \text { MINI) }\end{array}$ & $170(84 / 86)$ & $\begin{array}{l}\text { 1. Stepped-care program } \\
\text { 2. CAU }\end{array}$ \\
\hline $\begin{array}{l}\text { Willemse et } \mathrm{al}^{39} 2004 \\
\text { (the Netherlands) }\end{array}$ & $\begin{array}{l}\text { Adults (18-65 y) } \\
\text { Indicated }\end{array}$ & $\begin{array}{l}\text { Subthreshold depression, } \\
\text { no MDD in past } 12 \text { mo } \\
\text { (CIDI) }\end{array}$ & $216(109 / 107)$ & $\begin{array}{l}\text { 1. } \mathrm{CBT} \\
\text { 2. } \mathrm{CAU}\end{array}$ \\
\hline $\begin{array}{l}\text { Williams et al, }{ }^{48} 2000^{\mathrm{b}} \\
\text { (United States) }\end{array}$ & $\begin{array}{l}\text { Older adults ( } \geq 60 \mathrm{y}) \\
\text { Indicated }^{c}\end{array}$ & $\begin{array}{l}\text { Minor depression } \\
\text { (HRSD } \geq 10 ; \text { PRIME-MD) }\end{array}$ & $130(67 / 63)$ & $\begin{array}{l}\text { 1. PST-PC } \\
\text { 2. Placebo plus clinical management }\end{array}$ \\
\hline $\begin{array}{l}\text { Zhang et al, }{ }^{46} 2014^{f} \\
\text { (China) }\end{array}$ & $\begin{array}{l}\text { Adults }(\geq 18 \mathrm{y}) \\
\text { Indicatedc }\end{array}$ & $\begin{array}{l}\text { Subthreshold depression, } \\
\text { no MD (CES-D } \geq 16 \text {; SCID) }\end{array}$ & $240(119 / 121)$ & $\begin{array}{l}\text { 1. Stepped-care program } \\
\text { 2. CAU }\end{array}$ \\
\hline
\end{tabular}

$\mathrm{BDI}=$ Beck Depression Inventory; $\mathrm{CAU}=$ care as usual; $\mathrm{CB}=$ cognitive behavioral; $\mathrm{CBA}=$ cognitive behavioral approach; $\mathrm{CBT}=$ cognitive behavioral therapy; $\mathrm{CDI}=\mathrm{Children}$ 's Depression Inventory; CES-D = Center for Epidemiologic Studies of Depression; CIDI = Composite International Diagnostic Interview; DICA-R = Diagnostic Inventory for Children and Adolescents; DIS = Diagnostic Interview Schedule; DSM = Diagnostic and Statistical Manual of Mental Disorders; EPDS = Edinburgh Postnatal Depression Scale; HDRS = Hamilton Depression Rating Scale; HSCL-D = Hopkins Symptom Checklist for Depression; MD = major depression; $M D D=$ major depressive disorder; MDE = major depressive episode; MINI = Mini International Neuropsychiatric Interview; MOS = Medical Outcome Study; NR = not reported; PCA = person centered approach; PRIME$\mathrm{MD}=$ The Primary Care Evaluation of Mental Disorders; PRP = Penn Resiliency Program; PST = problem solving therapy; PST-PC $=$ problem solving treatment for primary care; SCID = Structured Clinical Interview for DSM-IV; SPPI = Standardized Polyvalent Psychiatric Interview.

Note: $C B, C B A$, and $C B T$ focus on the development of personal coping strategies that target solving current problems and changing unhelpful patterns in cognitions (eg, thoughts, beliefs, and attitudes), behaviors, and emotional regulation.

to $0.035 ; P=.432)$, nor after adjustment for the type of comparator $(\beta=-0.001 ; 95 \% \mathrm{CI},-0.059$ to 0.056 ; $P=.959)$.

\section{Publication Bias}

The funnel plot and Duval and Tweedie's trim-and-fill procedure $^{35}$ (Figure S1, Supplemental Appendix, available at http://www.annfammed.org/content/15/3/262/
suppl/DC1) were symmetric. After adjustment for potential publication bias, the pooled SMD was -0.163 (95\% CI, -0.256 to -0.070$)$. The Egger's test was nonsignificant (intercept $=-0.841 ; 95 \% \mathrm{CI}$, -2.395 to $0.713 ; P=.259)$. The fail-safe $\mathrm{N}$ was 48 , which means we would need to locate and include in our meta-analysis 48 studies with an SMD of 0 to reduce the pooled SMD obtained to a statistically 


\section{Intervention \\ Orientation}

(No. of Sessionsl

Format)

Clinician

\section{Main Outcome}

Follow-up

Risk

CB (6/individual)

Psychologists

Depressive symptoms

$11 \mathrm{wk}$ of Bias

Biopsychosocial person-

Primary care physicians who received a 10 - to $15-\mathrm{h}$ training workshop alized (3/individual)

Community nurse (health visitor) with 6 half-days training and access to regular supervision sessions

CBA (3/individual)

Community midwife with 8 -d training in psychological care ( $1 \mathrm{~d}$ exclusively in the use of the EPDS)

CB (6/individual) Psychologists, social workers, counselors

Psychoeducational and CB (5/group)

Primary care physicians with specific training in mental health and group therapy

CB (12/group)

Child psychologists, child social workers

CB (6/group) Psychologists

(HSCL-D-20 depression scale)

Incidence MD (CIDI) 6-12-18 mo 2 (IIhIII)

Proportion of women scoring $\geq 12$ EPDS

Proportion of women scoring $\geq 12$ EPDS

Depressive symptoms (HSCL-D-20 depression scale)

Prevalence of somatoform disorders (SPPI)

Depressive symptoms (CDI)

6-12-18 mo 5 (luhhll)

$22 w k$

4 (llhlhl)

11 wk 3 (llulhl)

Depressive symptoms (BDI)

9 (uhhhhl)

CB (6/individual by telephone)

CB (8/group)

CB (10/individual)

CB (CWD) (7/individual)

CB (6/individual)

CB (12/individual)
Student therapist, medical student, graduate nursing student

Psychologists

Home care nurse, specially trained (CBT-bibliotherapy), community psychiatric nurse (CBT + PST), primary care physician to give psychotropic medication (only for participants with continuously elevated CES-D scores)

Prevention specialist, clinician from a community mental health center

Psychologists, social workers, counselors

Social workers with at least 3 y counseling experience, primary care physician to give psychotropic medication (only for participants with continuously elevated CES-D scores) or referred to see a psychiatrist
Depressive symptoms (BDI)

Incidence of depression (DIS), depressive symptoms (BDI, CES-D)

Cumulative incidence of MDD (MINI)

Incidence of depression (CIDI), depressive symptoms (CES-D)

Depressive symptoms (HSCL-D-20 depression scale)

Incidence MD (SCID), depressive symptoms (CES-D)

\section{7 wk 7 (uhhlhl)}

6-12 mo

2 (IIhIII)

6-12-24 mo

4 (lhhlll)

$12 \mathrm{mo}$

4 (lhhlll)

11 wk

1 (IlullI)

$3-6-9-12-15 \mathrm{mo}$ 3 (Ilhlul)

${ }^{a}$ High score means higher risk of bias. Low risk $(l)=0$ points; unclear risk $(u)=1$ point; or high risk $(h)=2$ points; indicate rating of 6 quality criteria: random sequence, allocation concealment, blinding of participants and clinicians, blinding of outcome assessment, incomplete outcome data, selective reporting.

b These studies had 3 arms (paroxetine, placebo and problem-solving therapy), but we only used placebo vs problem-solving therapy.

c Patients with minor or subthreshold depression.

${ }^{\mathrm{d}}$ General population.

e Patients with some risk factors for depression.

${ }^{\mathrm{f}}$ In these studies, we collected only depression data.

nonsignificant level. Thus, we found no evidence of publication bias.

\section{Subgroup Analyses}

Subgroup analyses (Table 3) suggested that psychological and educational interventions to prevent depression in primary care were more effective when the comparator was care as usual or no intervention vs placebo.

\section{DISCUSSION}

We selected 14 RCTs, with a total of 7,365 nondepressed primary care attendees of different ages. Most of the 14 RCTs had a low risk of bias. In the metaanalysis we found a modest, although statistically significant, effect size for prevention of depression. The sensitivity analyses confirmed these results. We also found low heterogeneity and no evidence of publication bias. 
Figure 2. Forest plot of comparison: intervention vs control group, using a random-effects model.

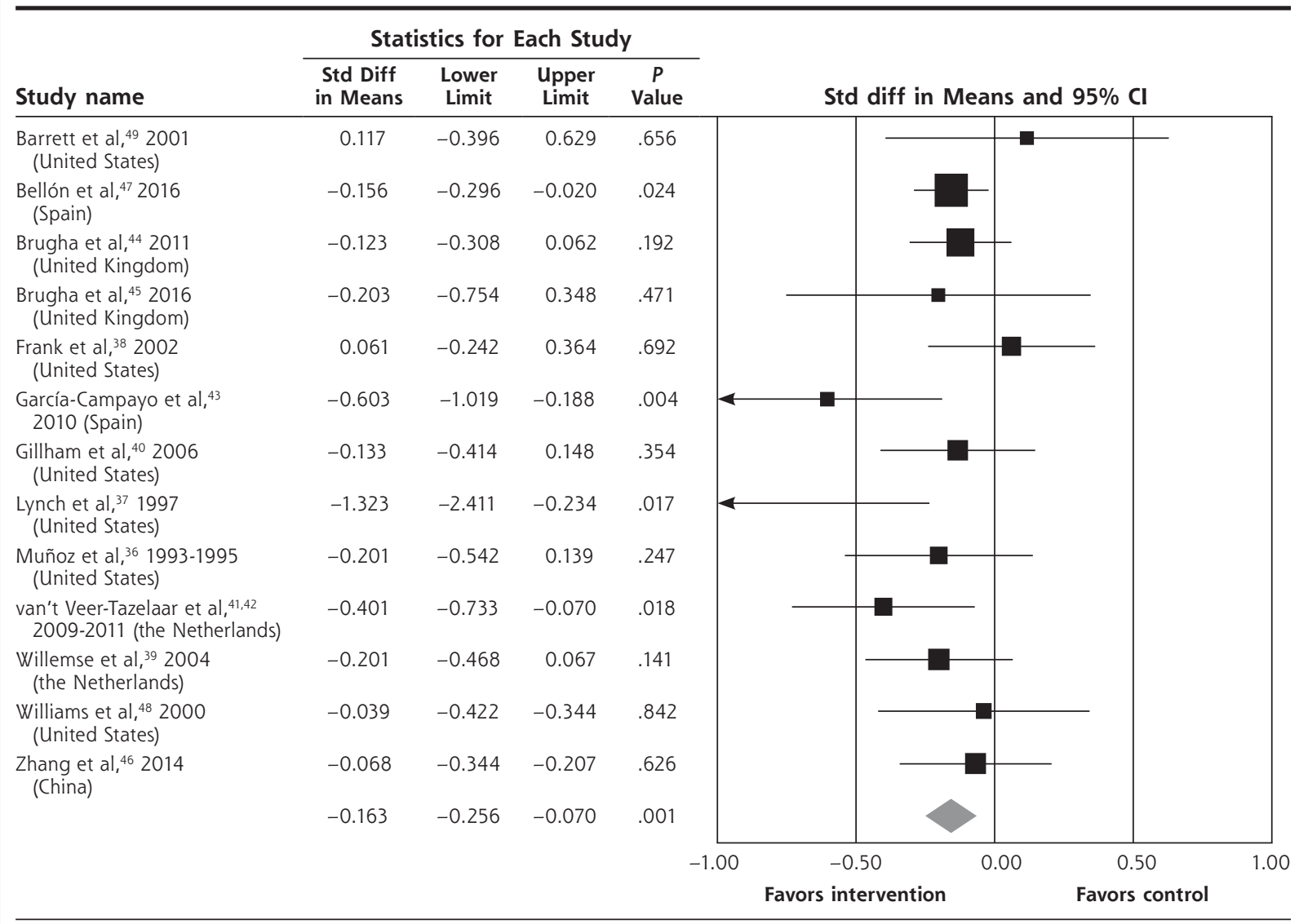

Std diff = standardized difference

To our knowledge, this meta-analysis is the first studying the effectiveness of psychological and educational interventions to prevent depression in primary care.

We included only RCTs that excluded depression at baseline; therefore, we are sure that effectiveness for prevention, not for treatment of depression, was assessed. In primary care we obtained an effect size, $\mathrm{SMD}=-0.163(\mathrm{OR}=0.74)$, very similar to the most recent meta-analysis of psychological interventions to prevent depression in all types of population (incidence rate ratio $($ IRR $)=0.79) .{ }^{24}$ Accordingly, the incidence of new episodes of depression could be reduced on average by $26 \%$ and $21 \%$ in our study and in the van Zoonen et al ${ }^{24}$ study, respectively. The effectiveness of psychological interventions to prevent depression is a robust finding, ${ }^{13-24}$ even though its effect size is small.

We only included $1 \mathrm{RCT}^{40}$ of psychological and educational interventions in adolescents to prevent depression in primary care; when this setting restriction was not used, however, most trials were limited to children and adolescents. ${ }^{23}$

In only $4 \mathrm{RCTs}^{43-45,47}$ were intervention clinicians primary care staff, and their pooled effect size (SMD $=-0.197)$ was not different when compared with mental health providers $(\mathrm{SMD}=-0.141)$; although there were too few RCTs to draw conclusions. We excluded $1 \mathrm{RCT}^{51}$ because the comparator was not care as usual, waiting list, or placebo; in both arms of this RCT, however, primary care physicians implemented interventions to prevent depression (motivational interviewing vs brief advice to engage adolescents with an Internet-based depression program). As compared with other types of clinicians, primary care staff may have various advantages, such as greater accessibility, closeness, knowledge of patients, and less stigma, as well as continuity of care and a comprehensive and holistic focus, ${ }^{52}$ though there may be certain drawbacks, such as the need for training and lack of time to carry out the intervention. ${ }^{53} \mathrm{~A}$ recent overview of reviews ${ }^{23}$ reported that most trials to prevent depression have been conducted by mental health specialists, to a lesser extent by educational staff (for children and adolescents), more sparsely by lay persons, and rarely by primary care professionals. Further trials with primary care staff as providers of depression interventions are needed. 


\begin{tabular}{|c|c|c|c|c|c|}
\hline Analysis & No. & SMD & $95 \% \mathrm{Cl}$ & $1^{2}$ & $\begin{array}{c}P \\
\text { Value }^{a}\end{array}$ \\
\hline \multicolumn{6}{|l|}{ Sensitivity } \\
\hline At first evaluation & 13 & -0.166 & -0.272 to -0.059 & 20.6 & .002 \\
\hline At last evaluation & 13 & -0.154 & -0.269 to -0.040 & 20.6 & .008 \\
\hline García-Campayo ${ }^{43}$ excluded & 12 & -0.143 & -0.220 to -0.065 & 0.00 & .000 \\
\hline Brugha ${ }^{45}$ excluded & 12 & -0.163 & -0.262 to -0.065 & 27.1 & .001 \\
\hline $\begin{array}{l}\text { García-Campayo } 0^{43} \text { and } \\
\text { Brugha }{ }^{45} \text { excluded }\end{array}$ & 11 & -0.141 & -0.223 to -0.059 & 4.9 & .001 \\
\hline \multicolumn{6}{|l|}{ Subgroup } \\
\hline \multicolumn{6}{|l|}{ Type of prevention } \\
\hline Indicated & 8 & -0.134 & -0.283 to 0.015 & 31.9 & .715 \\
\hline Selective & 4 & -0.236 & -0.434 to -0.037 & 29.9 & \\
\hline Universal & 1 & -0.156 & -0.293 to -0.020 & NA & \\
\hline \multicolumn{6}{|l|}{ Country } \\
\hline United States & 6 & -0.092 & -0.280 to 0.097 & 29.2 & .430 \\
\hline Europe & 6 & -0.211 & -0.322 to -0.099 & 17.9 & \\
\hline China & 1 & -0.068 & -0.344 to 0.207 & NA & \\
\hline \multicolumn{6}{|l|}{ Age } \\
\hline Adults & 10 & -0.156 & -0.268 to -0.045 & 28.7 & .903 \\
\hline Elderly & 2 & -0.233 & -0.588 to 0.121 & 49.2 & \\
\hline Adolescent & 1 & -0.133 & -0.414 to 0.148 & NA & \\
\hline \multicolumn{6}{|l|}{ Comparator } \\
\hline CAU/no intervention & 10 & -0.199 & -0.297 to -0.100 & 19.4 & .049 \\
\hline Placebo & 3 & 0.039 & -0.176 to 0.255 & 0.00 & \\
\hline \multicolumn{6}{|l|}{ Clinician } \\
\hline Primary care staff & 4 & -0.197 & -0.346 to -0.048 & 32.8 & .577 \\
\hline Mental health specialists & 9 & -0.141 & -0.272 to 0.010 & 23.3 & \\
\hline \multicolumn{6}{|l|}{ Intervention format } \\
\hline Individual & 10 & -0.139 & -0.235 to -0.043 & 13.8 & .327 \\
\hline Group & 3 & -0.278 & -0.539 to -0.017 & 43.2 & \\
\hline \multicolumn{6}{|l|}{ Number of sessions } \\
\hline $3-6$ & 7 & -0.172 & -0.377 to 0.033 & 51.22 & .736 \\
\hline $7-10$ & 4 & -0.193 & -0.322 to -0.065 & 0.00 & \\
\hline$>10$ & 2 & -0.100 & -0.297 to 0.097 & 0.00 & \\
\hline \multicolumn{6}{|l|}{ Sample size } \\
\hline$\leq 150$ & 5 & -0.274 & -0.602 to 0.054 & 58.8 & .752 \\
\hline $151-280$ & 6 & -0.143 & -0.269 to -0.017 & 0.00 & \\
\hline$>2,000$ & 2 & -0.145 & -0.254 to -0.035 & 0.00 & \\
\hline
\end{tabular}

to depression. ${ }^{54}$ Future studies including more active comparators would greatly improve the strength with which conclusions can be drawn about the effectiveness of preventing depression.

The pooled effect size of the first evaluation $(\mathrm{SMD}=-0.166)$ was very similar to the last evaluation $(\mathrm{SMD}=-0.154)$, and metaregression found no association between effect size and follow-up period. In other meta-analyses, however, the effect size of the first evaluations was greater than for the last evaluations. ${ }^{13,24}$

Interventions based on interpersonal therapy might be more effective than those based on CBT. ${ }^{13,24}$ In our study the psychological and educational interventions were mostly based on the principles of CBT, so we have no data to discuss the superiority of any particular kind of intervention. Only 1 RCT had a completely different approach to all the others. ${ }^{47}$ This RCT was implemented by primary care physicians, who measured each patient's individual risk for developing depression, identifying in each patient specific risk factors for depression that are amenable to change. This information was then used with each patient to improve knowledge and alter behavior. This RCT was also the only one included in our study that involved universal prevention. Although the RCTs by Brugha et $\mathrm{a}^{44,45}$ could have been considered to involve universal prevention, including puerperal and pregnant women implies in itself that the intervention was applied in a high-risk population (selective prevention). In our meta-analysis, selective prevention seemed to have a greater effect $(\mathrm{SMD}=-0.236)$ than indicated prevention $(\mathrm{SMD}=-0.134)$; this difference, however, was not statistically significant, and only 4 RCTs included selective prevention.

Our study has several limitations that should be considered. First, with the use of truncation and the choice of expression for the terms in PubMed, we per- 
formed a search with less sensitivity; therefore, some potentially useful articles were not included. This loss might be minimized, however, by the search in the other 5 databases and the references of relevant previous reviews, meta-analyses, and retrieved articles. Second, the number of studies that satisfied all our inclusion criteria was relatively small (14 RCTs). Thus, there was a lack of statistical power to find differences in subgroup and meta-regression analyses. Accordingly, these results should be interpreted with caution. Third, 9 RCTs measured only depressive symptoms as outcome. Though this procedure is valid, it is less rigorous than standardized diagnostic interviews; reduction of depressive symptoms, however, also has a positive impact on quality of life and cost. ${ }^{55}$ Fourth, although 6 RCTs had follow-up periods of more than 12 months, only 4 reached 24 months or more. Another 4 RCTs had follow-up periods that were too short (11 or fewer weeks). Consequently, we are unable to draw clear conclusions about the long-term effect.

We found a modest but positive effect of psychological and educational interventions to prevent depression in primary care. According to our results, primary care managers and physicians could implement programs and interventions to prevent depression. Not enough information is available, however, about what program or intervention is more efficient in primary care.

To read or post commentaries in response to this article, see it online at http://www.AnnFamMed.org/content/15/3/262.

Key words: depression/prevention $\varepsilon$ control; delivery of health care; primary health care; systematic review; meta-analysis; psychological interventions; educational interventions

Submitted May 31, 2016; submitted, revised, October 22, 2016; accepted November 18, 2016.

Author affiliations: Unidad de Investigación, Distrito de Atención Primaria Málaga-Guadalhorce, Málaga, Spain (Conejo-Cerón, Moreno-Peral, Navas-Campaña, Bellón); Red de Investigación en Actividades Preventivas y de Promoción de la Salud (redIAPP), Barcelona, Spain (ConejoCerón, Moreno-Peral, Rodríguez-Morejón, Motrico, Navas-Campaña, Rigabert, Martín-Pérez, Rodríguez-Bayón, Ballesta-Rodríguez, Luna, García-Campayo, Roca, Bellón); Instituto de Investigación Biomédica de Málaga (IBIMA), Malaga, Spain (Conejo-Cerón, Moreno-Peral, RodríguezMorejón, Bellón); Departamento de Personalidad, Evaluación y Tratamiento Psicológico, Universidad de Málaga, Malaga, Spain (RodríguezMorejón); Departamento de Psicología, Universidad Loyola Andalucía, Sevilla, Spain (Motrico, Rigabert); Centro de Salud Marquesado, Área Nordeste de Granada, Granada, Spain (Martín-Pérez); Centro de Salud San José, Linares, Jaén, Spain (Rodríguez-Bayón); Centro de Salud Federico del Castillo, Jaén, Spain (Ballesta-Rodríguez); Departamento de Bioestadística. Universidad de Granada, Granada, Spain (Luna); Instituto de Investigación Biosanitaria de Granada (ibs.GRANADA), Granada, Spain (Luna); Departamento de Psiquiatría, Hospital Universitario Miguel Servet, Universidad de Zaragoza, Instituto de Investigación Sanitaria de Aragón, Zaragoza, Spain (García-Campayo); Institut Universitari d'Investigació en Ciències de la Salut (IUNICS-IDISPA), University of Balearic Islands, Palma de Mallorca, Spain (Roca); Centro de Salud El Palo,
Málaga, Spain (Bellón); Departamento de Medicina Preventiva, Salud Pública y Psiquiatría, Universidad de Málaga, Málaga, Spain (Bellón).

Funding support: The following institutions contributed financial support: Instituto de Salud Carlos III and the European Regional Development Fund, "Una manera de hacer Europa" (grant PI12/02755), Consejería de Salud de la Junta de Andalucía (grant PI-0583-2012), and Red de Investigación en Actividades Preventivas y Promoción de la Salud (redIAPP) (grant RD06/0018).

Acknowledgments: The authors thank the Primary Care District of Malaga for their support.

Supplementary materials: Available at http://www.AnnFamMed. org/content/15/3/262/suppl/DC1/.

\section{References}

1. World Health Organization. Depression. http://www.who.int/mediacentre/factsheets/fs369/en/index.html Published 2012. Accessed May 13, 2014.

2. Bromet E, Andrade LH, Hwang I, et al. Cross-national epidemiology of DSM-IV major depressive episode. BMC Med. 2011;9:90.

3. King M, Nazareth I, Levy G, et al. Prevalence of common mental disorders in general practice attendees across Europe. Br J Psychiatry. 2008;192(5):362-367.

4. Möller HJ. Suicide, suicidality and suicide prevention in affective disorders. Acta Psychiatr Scand. 2003;(418):73-80.

5. Cuijpers P, Vogelzangs N, Twisk J, Kleiboer A, Li J, Penninx BW. Comprehensive meta-analysis of excess mortality in depression in the general community versus patients with specific illnesses. Am J Psychiatry. 2014;171(4):453-462.

6. Murray CJL, Vos T, Lozano R, et al. Disability-adjusted life years (DALYs) for 291 diseases and injuries in 21 regions, 1990-2010: a systematic analysis for the Global Burden of Disease Study 2010. [published correction appears in Lancet. 2013;381(9867):628]. Lancet. 2012;380(9859):2197-2223.

7. Mathers CD, Loncar D. Projections of global mortality and burden of disease from 2002 to 2030. PLoS Med. 2006;3(11):e442.

8. Chisholm D, Sanderson K, Ayuso-Mateos JL, Saxena S. Reducing the global burden of depression: population-level analysis of intervention cost-effectiveness in 14 world regions. Br J Psychiatry. 2004;184:393-403.

9. Muñoz RF, Cuijpers P, Smit F, Barrera AZ, Leykin Y. Prevention of major depression. Annu Rev Clin Psychol. 2010;6:181-212.

10. National Institute of Mental Health. Strategic plan for research. NIH Publication Number 15-6368. https://www.nimh.nih.gov/ about/strategic-planning-reports/nimh_strategicplanforresearch_ 508compliant_corrected_final_149979.pdf. Published May $201 \overline{5}$. Accessed Apr 17, 2017.

11. Hackett ML, Anderson CS, House A, Halteh C. Interventions for preventing depression after stroke. Cochrane Database Syst Rev. 2008;(3):CD003689.

12. Kavanagh J, Oliver S, Lorenc T, et al. School-based cognitivebehavioural interventions: a systematic review of effects and inequalities. Health Sociol Rev. 2009;18(1):61-78.

13. Cuijpers P, van Straten A, Smit F, Mihalopoulos C, Beekman A. Preventing the onset of depressive disorders: a meta-analytic review of psychological interventions. Am J Psychiatry. 2008;165(10):1272-1280.

14. Cuijpers P, Muñoz RF, Clarke GN, Lewinsohn PM. Psychoeducational treatment and prevention of depression: the "Coping with Depression" course thirty years later. Clin Psychol Rev. 2009;29(5):449-458.

15. De Silva M, Maclachlan M, Devane D, et al. Psychosocial interventions for the prevention of disability following traumatic physical injury. Cochrane Database Syst Rev. 2009;7(4):CD006422. 
16. Merry SN, Hetrick SE, Cox GR, Brudevold-Iversen T, Bir JJ, McDowell H. Psychological and educational interventions for preventing depression in children and adolescents. Cochrane Database Syst Rev. 2011;12(12):CD003380.

17. Vázquez $F$, Blanco $V$, Torres $A$, Otero $P$, Hermida E. The efficacy of indicated prevention of depression: a review. Anales de Psicologia. 2014;30(1):9-24.

18. Neil AL, Christensen H. Australian school-based prevention and early intervention programs for anxiety and depression: a systematic review. Med J Aust. 2007;186(6):305-308.

19. Shaw E, Levitt C, Wong S, Kaczorowski J, McMaster University Postpartum Research Group. Systematic review of the literature on postpartum care: effectiveness of postpartum support to improve maternal parenting, mental health, quality of life, and physical health. Birth. 2006;33(3):210-220.

20. Stice E, Shaw H, Bohon C, Marti CN, Rohde P. A meta-analytic review of depression prevention programs for children and adolescents: factors that predict magnitude of intervention effects. J Consult Clin Psychol. 2009;77(3):486-503.

21. van der Waerden JE, Hoefnagels C, Hosman CM. Psychosocial preventive interventions to reduce depressive symptoms in low-SES women at risk: a meta-analysis. J Affect Disord. 2011;128(1-2):10-23.

22. Calear AL, Christensen H. Systematic review of school-based prevention and early intervention programs for depression. J Adolesc. 2010;33(3):429-438.

23. Bellón JA, Moreno-Peral P, Motrico E, et al. Effectiveness of psychological and/or educational interventions to prevent the onset of episodes of depression: A systematic review of systematic reviews and meta-analyses. Prev Med. 2015;76 Suppl:S22-32.

24. van Zoonen K, Buntrock C, Ebert DD, et al. Preventing the onset of major depressive disorder: a meta-analytic review of psychological interventions. Int J Epidemiol. 2014;43(2):318-329.

25. Marshall M. A precious jewel-the role of general practice in the English NHS. N Engl J Med. 2015;372(10):893-897.

26. Moher D, Liberati A, Tetzlaff J, Altman DG, et al. Preferred reporting items for systematic reviews and meta-analyses: the PRISMA statement. BMJ. 2009;339:b2535.

27. Piantadosi S. Clinical Trials: A Methodological Perspective, 2nd Edition. New York, NY: John Wiley \& Sons; 2005.

28. Muñoz RF, Beardslee WR, Leykin Y. Major depression can be prevented. Am Psychol. 2012;67(4):285-295.

29. Cohen J. A coefficient of agreement for nominal scales. Educ Psychol Meas. 1960;20(1):37-46.

30. Fleiss JL. Statistical Methods for Rates and Proportions, 2nd Edition. New York, NY: John Wiley; 1981.

31. Higgins JPT, Green S, eds. Cochrane Handbook for Systematic Reviews of Interventions. Version 5.1.0. Updated March 2011. http://handbook.cochrane.org/.

32. Fleiss JL. The Design and Analysis of Clinical Experiments. New York, NY: John Wiley \& Sons; 1986.

33. Cohen J. Statistical Power Analysis for the Behavioral Sciences, 2nd Edition. Hillsdale, NJ: Erlbaum; 1988.

34. Higgins JP, Thompson SG, Deeks JJ, Altman DG. Measuring inconsistency in meta-analyses. BMJ. 2003;327(7414):557-560.

35. Duval S, Tweedie R. Trim and fill: A simple funnel-plot-based method of testing and adjusting for publication bias in metaanalysis. Biometrics. 2000;56(2):455-463.

36. Muñoz R, Ying YW, Bernal G, et al. Prevention of depression with primary care patients: a randomized controlled trial. Am J Community Psychol. 1995;23(2):199-222.

37. Lynch DJ, Tamburrino MB, Nagel R. Telephone counseling for patients with minor depression: preliminary findings in a family practice setting. J Fam Pract. 1997;44(3):293-298.
38. Frank E, Rucci $P$, Katon W, et al. Correlates of remission in primary care patients treated for minor depression. Gen Hosp Psychiatry. 2002;24(1):12-19.

39. Willemse GR, Smit F, Cuijpers P, Tiemens BG. Minimal-contact psychotherapy for sub-threshold depression in primary care. Randomised trial. Br J Psychiatry. 2004;185:416-421.

40. Gillham JE, Hamilton J, Freres DR, Patton K, Gallop R. Preventing depression among early adolescents in the primary care setting: a randomized controlled study of the Penn Resiliency Program. J Abnorm Child Psychol. 2006;34(2):203-219.

41. van't Veer-Tazelaar PJ, van Marwijk HW, van Oppen P, et al. Stepped-care prevention of anxiety and depression in late life: a randomized controlled trial. Arch Gen Psychiatry. 2009;66(3):297-304.

42. van't Veer-Tazelaar PJ, van Marwijk HW, van Oppen P, et al. Prevention of late-life anxiety and depression has sustained effects over 24 months: a pragmatic randomized trial. Am J Geriatr Psychiatry. 2011;19(3):230-239.

43. García-Campayo J, Arevalo E, Claraco LM, Alda M, Lopez del Hoyo Y. A prevention programme for somatoform disorders is effective for affective disorders. J Affect Disord. 2010;122(1-2):124-132.

44. Brugha TS, Morrell CJ, Slade P, Walters SJ. Universal prevention of depression in women postnatally: cluster randomized trial evidence in primary care. Psychol Med. 2011;41(4):739-748.

45. Brugha TS, Smith J, Austin J, et al. Can community midwives prevent antenatal depression? An external pilot study to test the feasibility of a cluster randomized controlled universal prevention trial. Psychol Med. 2016;46(2):345-356.

46. Zhang DX, Lewis G, Araya R, et al. Prevention of anxiety and depression in Chinese: a randomized clinical trial testing the effectiveness of a stepped care program in primary care. J Affect Disord. 2014;169:212-220.

47. Bellón JA, Conejo-Cerón S, Moreno-Peral P, et al. Intervention to prevent major depression in primary care: a cluster-randomized trial. Ann Intern Med. 2016;164(10):656-665. doi:10.7326/ M14-2653.

48. Williams JW Jr, Barrett J, Oxman T, et al. Treatment of dysthymia and minor depression in primary care: A randomized controlled trial in older adults. JAMA. 2000;284(12):1519-1526.

49. Barrett JE, Williams JW Jr, Oxman TE, et al. Treatment of dysthymia and minor depression in primary care: a randomized trial in patients aged 18 to 59 years. J Fam Pract. 2001;50(5):405-412.

50. González González S, Fernández Rodríguez C, Pérez Rodríguez J, Amigo I. [Depression secondary prevention in primary care]. Psicothema. 2006;18(3):471-477.

51. Hoek W, Marko M, Fogel J, et al. Randomized controlled trial of primary care physician motivational interviewing versus brief advice to engage adolescents with an Internet-based depression prevention intervention: 6-month outcomes and predictors of improvement. Transl Res. 2011;158(6):315-325.

52. Bellón JÁ, Conejo-Cerón S, Moreno-Peral P, et al. Preventing the onset of major depression based on the level and profile of risk of primary care attendees: protocol of a cluster randomised trial (the predictD-CCRT study). BMC Psychiatry. 2013;13:171.

53. Rubio-Valera $M$, Pons-Vigués $M$, Martínez-Andrés $M$, Moreno-Peral $P$, Berenguera $A$, Fernández $A$. Barriers and facilitators for the implementation of primary prevention and health promotion activities in primary care: a synthesis through meta-ethnography. PLoS One. 2014;9(2):e89554.

54. Cuijpers $P$, Cristea IA. What if a placebo effect explained all the activity of depression treatments? World Psychiatry. 2015;14(3): 310-311.

55. Lynch FL, Hornbrook M, Clarke GN, et al. Cost-effectiveness of an intervention to prevent depression in at-risk teens. Arch Gen Psychiatry. 2005;62(11):1241-1248. 